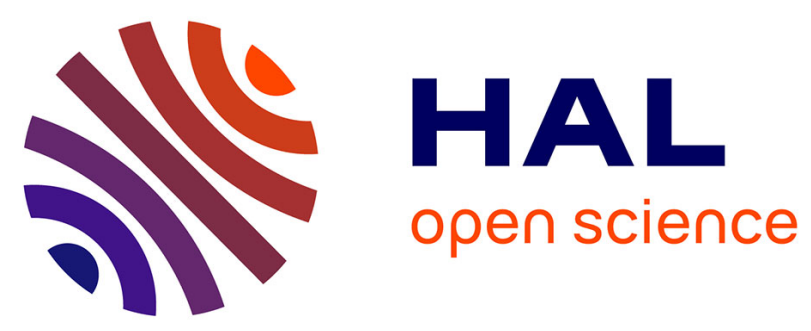

\title{
Optimization and Simulation of Fertilizer Guide Device Parameters Based on EDEM Software
}

\author{
Hai Ding, Xiaofei An, Guangwei Wu, Liwei Li, Qingzhen Zhu
}

\section{To cite this version:}

Hai Ding, Xiaofei An, Guangwei Wu, Liwei Li, Qingzhen Zhu. Optimization and Simulation of Fertilizer Guide Device Parameters Based on EDEM Software. 11th International Conference on Computer and Computing Technologies in Agriculture (CCTA), Aug 2017, Jilin, China. pp.377-388, 10.1007/978-3-030-06179-1_38. hal-02111539

\section{HAL Id: hal-02111539 \\ https://hal.inria.fr/hal-02111539}

Submitted on 26 Apr 2019

HAL is a multi-disciplinary open access archive for the deposit and dissemination of scientific research documents, whether they are published or not. The documents may come from teaching and research institutions in France or abroad, or from public or private research centers.
L'archive ouverte pluridisciplinaire HAL, est destinée au dépôt et à la diffusion de documents scientifiques de niveau recherche, publiés ou non, émanant des établissements d'enseignement et de recherche français ou étrangers, des laboratoires publics ou privés. 


\title{
Optimization and simulation of fertilizer guide device parameters based on EDEM software
}

\author{
Ding Hai $^{1,2}$, An Xiaofei ${ }^{2,3(凶)}$, Wu Guangwei ${ }^{2,3}$, Li Liwei ${ }^{2,3}$, Zhu Qingzhen ${ }^{1,2,3}$ \\ 1. College of Mechanical and Electronic Engineering, Northwest A\&F University, Yangling 712100, China; \\ 2.Beijing Research Center of Information Technology in Agriculture, Beijing 100097, China; \\ 3.National Research Center of Information Technology in Agriculture, Beijing, 100097, China
}

\begin{abstract}
In order to match the fertilizer line and seed line, fertilizer application should be homogeneous enough. A new fertilizer guide device was designed. It was consisted of fertilizer guide groove, shunted parts and cover plate. According to the theoretical analysis and practical experience, the main parameters affecting the effect of applying fertilizer were specified, including groove installation angle, the angle and the position of shunt part. With the single factor simulation experiment, the optimization and simulation of fertilizer guide device parameters were carried out based on EDEM software. The selected parameter interval was determined firstly. And then 10 set experiment results were obtained within the determined range. When the angle of diverter component was $33^{\circ}$, the distance was $25 \mathrm{~mm}$, and the angle of guide groove installation was $37^{\circ}$, the best fertilizer application result was obtained. The simulation experiment provided a reference for the guide flow device design.
\end{abstract}

Keywords: Fertilizer diversion; Precision fertilization; EDEM; Simulation

\section{Introduction}

Fertilizer application was an important part in wheat growth period. In order to match the fertilizer line and seed line, uniform fertilizer distribution was the first step. At present, it has the phenomenon of accumulation or uneven distribution in the fertilizer application. Domestic and foreign scholars have researched on fertilizer mechanism parameter to improve the fertilizer effect ${ }^{[1,2,3,4,5,6,7,8]}$. Zeng $\mathrm{Min}^{[4]}$ proposed that appropriate agricultural policies should be adopted and the level of agricultural machinery should also be improved. Wei Guojian ${ }^{[5]}$ designed 1GF-200 rice rotary tillage fertilizer applicator, with the rectangular tube and sector fertilizer export, which could help improve fertilizer uniformity in the rice field. Bytesting experimental prototype, within 50 meters, the uniformity coefficient of horizontal fertilization was $21 \%$; the apiece row consistency variability coefficient was $2.28 \%$; the stability variability coefficient of the full fertilizer quantity was $1.09 \%$. Experimental results showed that it had a rational design and reliable function and its working quality could be easily applied to agricultural requirement. Dun Guoqiang designed fertilizer allocation device to layered fertilization, which was typical of fertilizer uniform distribution device and Fertilizer adjustable ratio device to achieve the uniform of application. And by the simulation and the experimental verify, the qualified coefficient was 0.928 and the Fluctuation coefficient was 78 . So the device was a rational design and could improve use efficiency of fertilizer. But referring to lots of research, the literature of wheat fertilizer guide device could not be found. As a result, it was needed to design a new kind of fertilizer guide device to improve the uniformity of fertilizer distribution.

The purpose of this study was to design a new fertilizer guide device to improve the uniformity of the 
base fertilizer application. And then the fertilizer simulation analysis was carried out to obtain the optimization parameter based on EDEM software.

\section{Structure and Principle}

The fertilizer guide device was consisted of fertilizer guide groove, shunt parts and cover plate. Figure 1 showed the device model. The fertilizer was discharged with three parts by the shunt parts. The cover plate could prevent fertilizer from splashing. We designed pattern draft for the guide device to make fertilizer discharged smoothly. The three triangular shunt parts were installed at the bottom of the device. The triangle configuration made it running smoothly. The cover plate size could cover the shunt parts. Otherwise, fertilizer would be blocked.

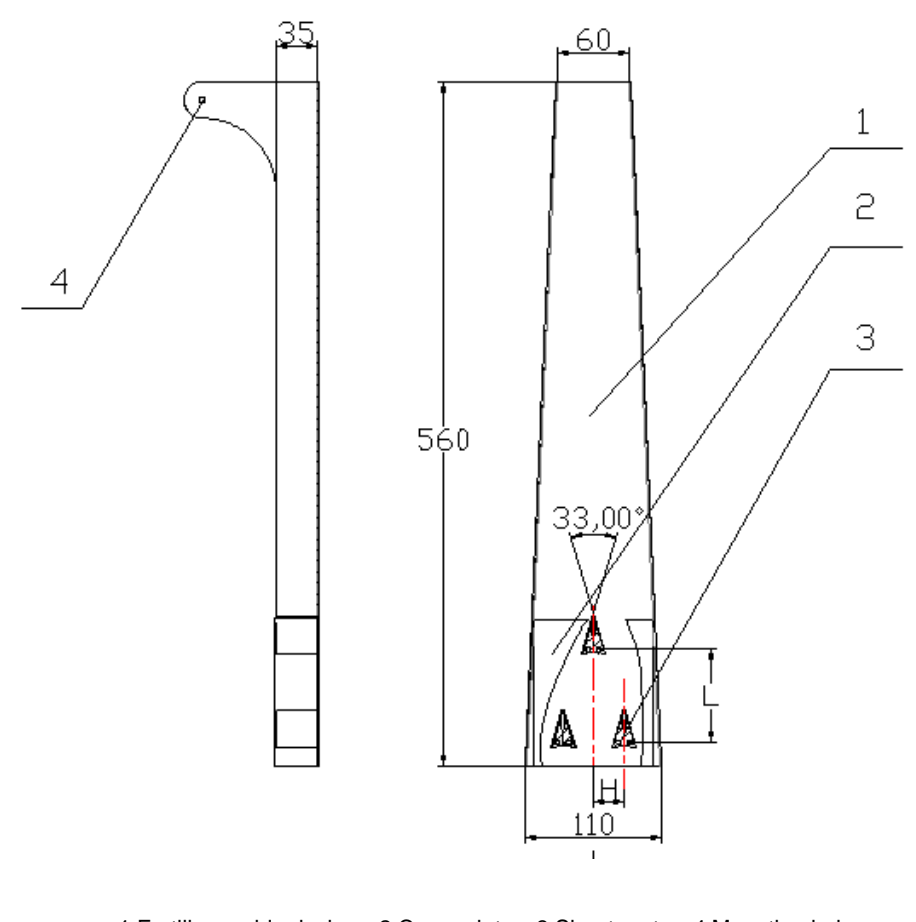

Fig.1 Assembly drawing of fertilizing device

\section{Key Component Parameter Designing}

\section{(1) Fertilizer guide groove designing}

The total length of the fertilizer guide groove was $560 \mathrm{~mm}$. The diameter of the fertilizer outlet was $40 \mathrm{~mm}$. And the width of the top of the fertilizer guide groove was $60 \mathrm{~mm}$. There were eight fertilizer outlets on the fertilizer mechanism. The total width of fertilizer mechanism was $2.0 \mathrm{~m}$.Limited by the dimensions of fertilizer mechanism, the base of the fertilizer guide groove was determined about $110 \mathrm{~mm}$. The installation angle of the fertilizer guide device had influence on the effect of fertilizer distribution. After the preliminary simulation, the angle was determined by the range of $30^{\circ}-50^{\circ}$. 

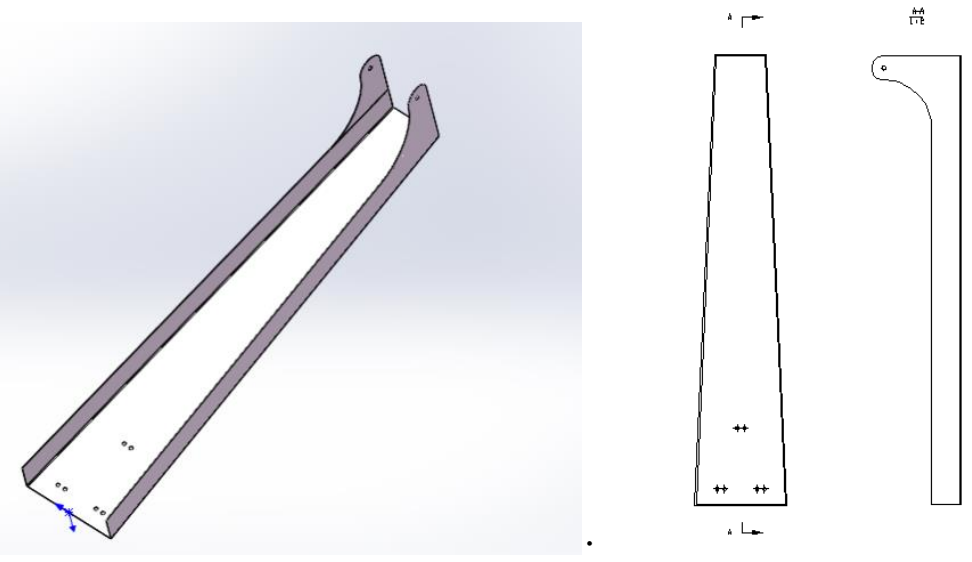

Fig.2 Fertilizer guide device

\section{(2) Shunt part designing}

The shunt part was designed as triangle structure method, with fillet of the head, installed with M4 bolts. The opening angle of the shunt component was an important factor affecting the distributary effect of the fertilizer. If the opening angle was too large, as a result, fertilizer would be blocked. The pretreatment result showed that the middle export discharged $7.05 \mathrm{~g}$ when the opening angle was up to $42^{\circ}$ and both sides were $13.1 \mathrm{~g}$ and $13.7 \mathrm{~g}$ under condition of 1000 particles. The side total weight was twice than that of the middle. So the shunt parts opening angel should be less than $42^{\circ}$.Meanwhile it should be greater than $30^{\circ}$ on the consideration of the mounting hole size.
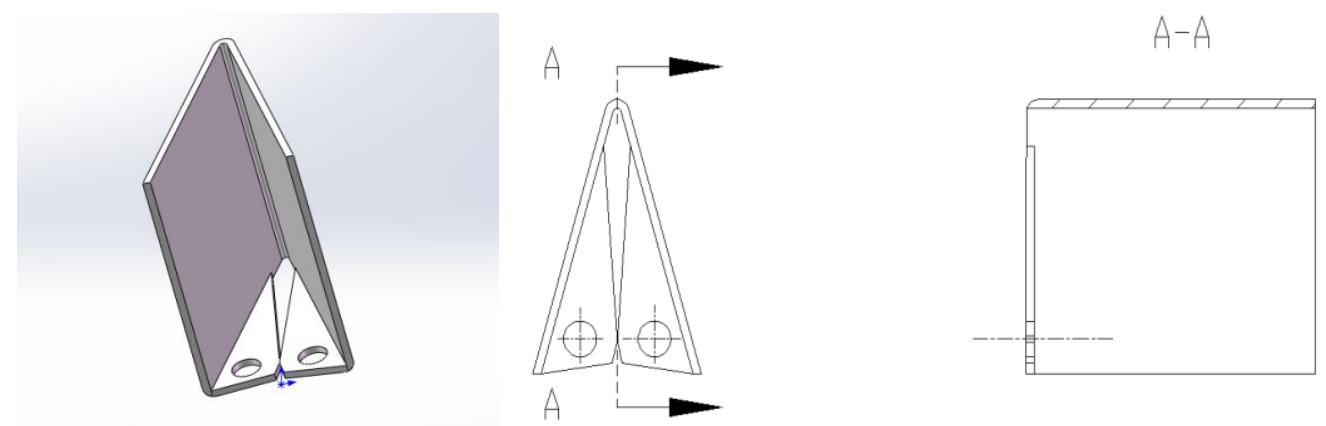

Fig.3 The shunt part

\section{(3) Cover plate designing}

The cover plate was used to prevent fertilizer from splashing. It was need to cover the shunt parts exactly. As for the width, the cover plate shall be fully fitted to the inner wall of the fertilizer guide device in order to prevent the fertilizer from escaping from both sides. There was mounting hole on the cover. Its position was equal to the shunt parts. The adjustable vertical distance of the installation hole was longer than the transverse. And the two installation hole were symmetrical distribution. 

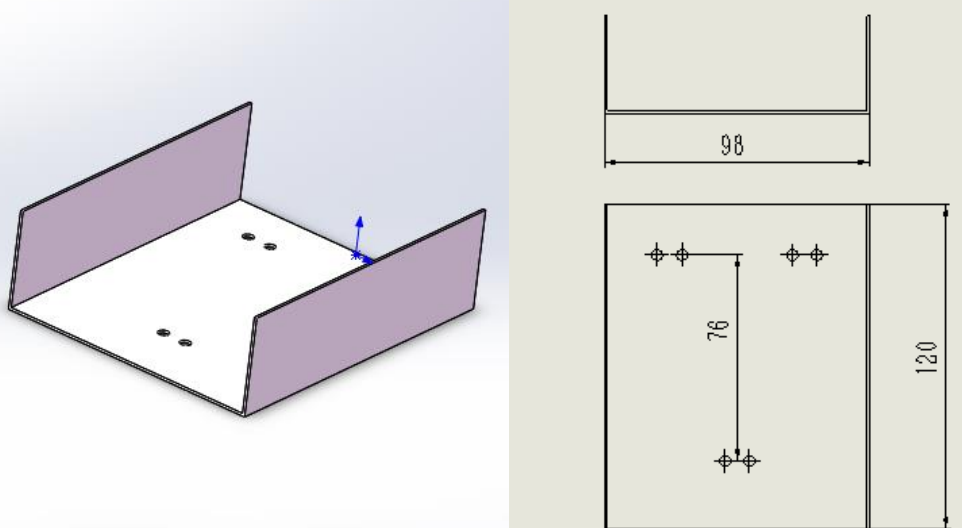

Fig.4 The cover plate

\section{Simulation Experiment of Parameter Optimization for Fertilizer Device}

The effect of fertilizer distribution was closely related to the installation angle of the fertilizer guide device, the opening angel and position of the shunt parts. The simulation model of device was established based on EDEM software.

\subsection{Simulation Parameter Setting}

\section{(1) Experimental Parameter Setting}

Referring to the relevant research ${ }^{[9-11]}$, the Le Sol compound fertilizer was selected as experiment material. Subsequently, thirty particles were selected to determine the average diameter of fertilizer and the mass of particle. Table 1 was the particle statistic data with the 30 selected particles. The final average mass was $0.0335 \mathrm{~g}$.

Table 1 Particle parameter statistics

\begin{tabular}{cc}
\hline Particle parameters & Values \\
\hline Average mass/g & 0.0335 \\
Mass standard deviation $/ \mathrm{g}$ & 0.0171 \\
Average radius $/ \mathrm{mm}$ & 1.6405 \\
Radius standard deviation $/ \mathrm{mm}$ & 0.1526 \\
\hline
\end{tabular}

The fertilizer particles were modeled by sphere. The following equation was material density of the fertilizer particles.

$$
\rho_{f}=\frac{m_{f}}{V_{f}}=\frac{m_{f}}{\frac{4}{3} \pi\left(\frac{D_{f}}{2}\right)^{3}}=\frac{6 m_{f}}{\pi D_{f}{ }^{3}}
$$

$\rho_{f}$ was particle density, $\mathrm{g} / \mathrm{cm} 3 ; m_{f}$ was particle mass, $\mathrm{g} ; V_{f}$ was particle volume, $\mathrm{mm}^{3} ; D_{f}$ was average particle diameter, $\mathrm{mm}$, average particle density $\rho_{f}=1.861 \mathrm{~g} / \mathrm{cm}^{3}$; bulk density of fertilizer particle was $0.982 \mathrm{~g} / \mathrm{cm}^{3}$.

\section{(2) Model variable parameter setting}


Hertz-mindlin(no-slip) model was adopted to simulate the collision of particle to particle, particle to grooved and box. Table 2 was detail pre-treatment parameter value. The simulation particle diameter was $1.64 \mathrm{~mm}$. The quality attributes of fertilizer particles were calculated automatically by EDEM software.

Table 2 Pre-treatment parameter setting

\begin{tabular}{ccc}
\hline Item & Property & Value \\
\hline \multirow{2}{*}{ particles } & Poisson ratio & 0.25 \\
& Shear modulus/ Pa & $1.0 \times 107$ \\
Grooved wheel, housing & density $/\left(\mathrm{kg} \cdot \mathrm{m}^{-3}\right)$ & 1861 \\
& Poisson ratio & 0.394 \\
particle-particle & Shear modulus & $3.189 \times 10^{8}$ \\
& density $/\left(\mathrm{kg} \cdot \mathrm{m}^{-3}\right)$ & 1335 \\
& Coefficient of restitution & 0.6 \\
Particle-grooved wheel, housing & Coefficient of static friction & 0.4 \\
& Coefficient of kinetic friction & 0.01 \\
& Coefficient of restitution & 0.5 \\
\hline
\end{tabular}

We used solidworks2012 to establish 3D geometry model. At the same time, three storage boxes were designed at the bottom of device export to collect three parts of fertilizers from the outlet. And then simulate and measure the total quality of the three regions of fertilizers, respectively.

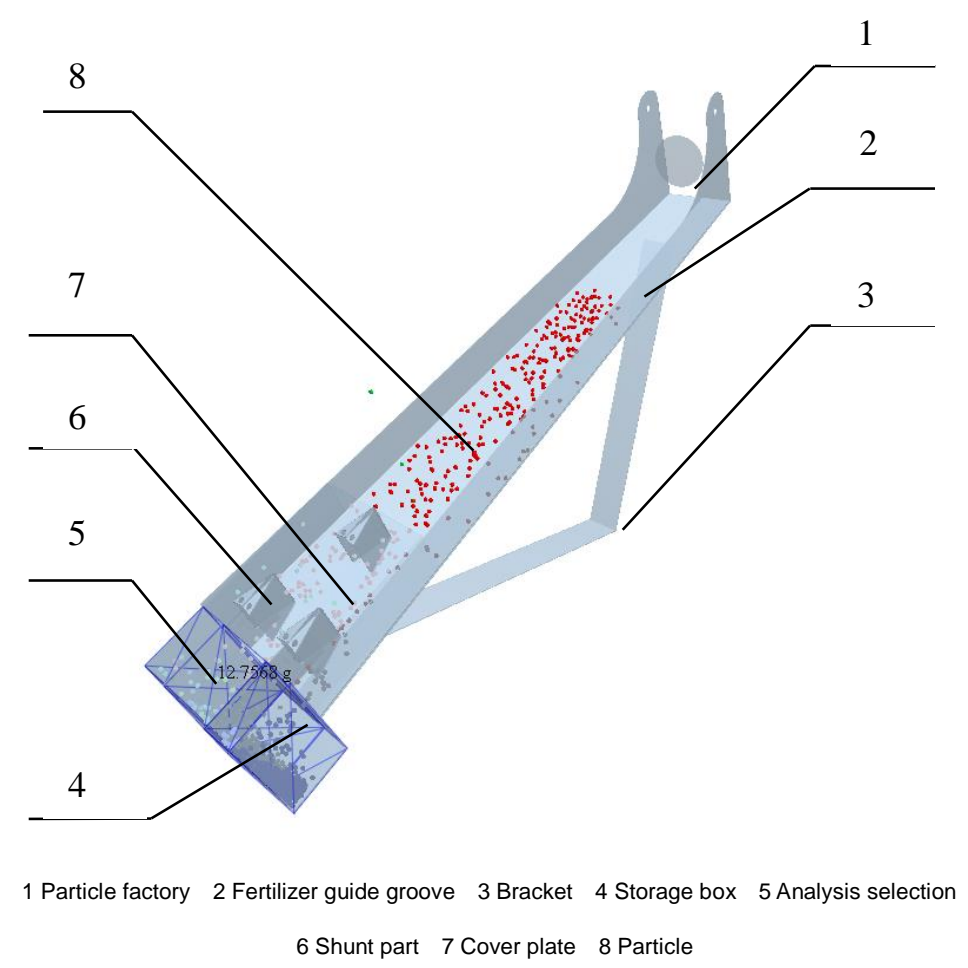

Fig 5 EDEM simulation model of fertilizer application

The 3D model was saved in IGS format and was imported into the EDEM software. The total amount 
of particles was set to 1000and the rate of product was 1000 particles per second. The gravitational acceleration was $-9.81 \mathrm{~m} / \mathrm{s}^{2}$. The simulation step was $1.53 \times 10^{-5}$. Total simulation time was 2 seconds.

\subsection{Simulation Analysis and Parameter Optimization}

\section{(1) Simulate shunt part opening}

In order to certain the optimal shunt part opening angle, ten groups of opening angle sample, from $30^{\circ}$ to $40^{\circ}$ were selected with interval of $1^{\circ}$. According to table 1 and table 2 , all the parameters were set. The corresponding simulated result was shown in the figure 6.

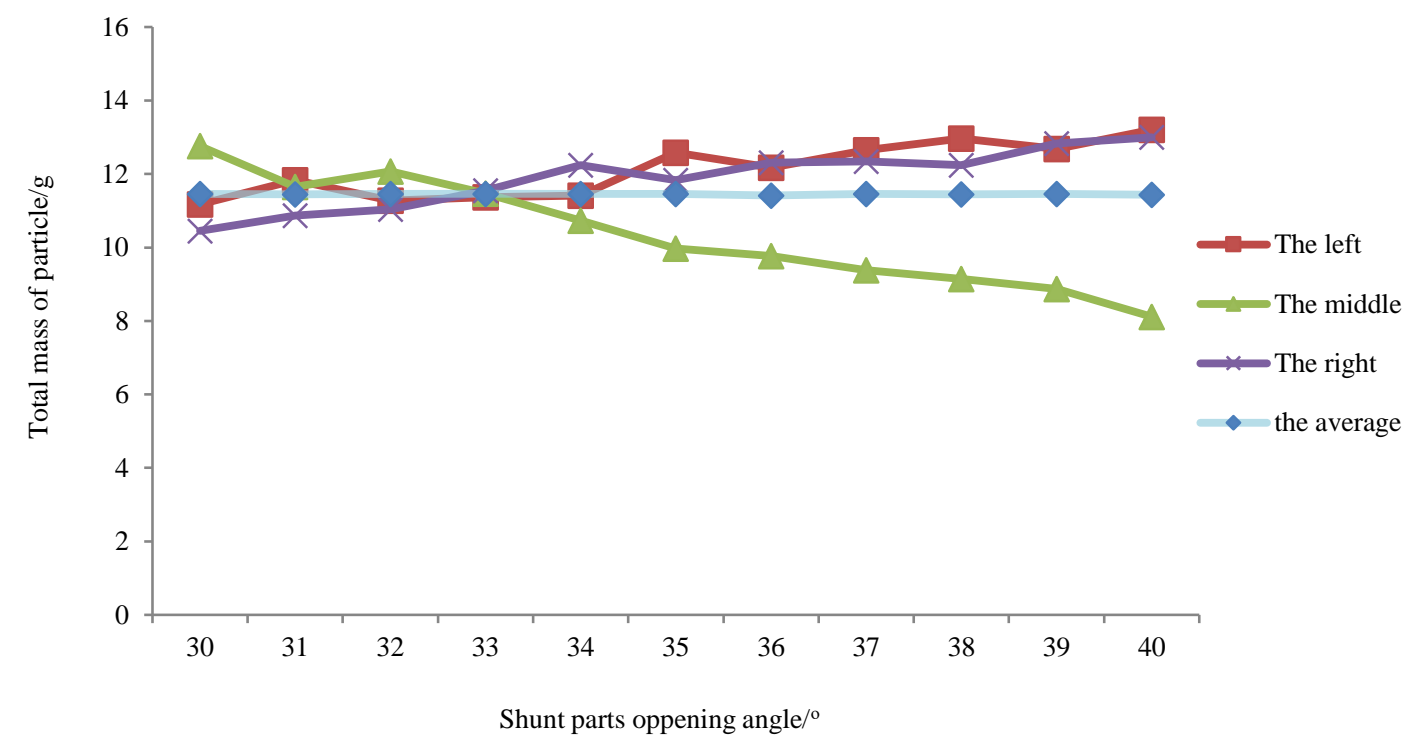

Fig 6 Simulation of shunt parts opening

With the increase of the shunting part opening angle, the fertilizer amount at both sides of the outlet increased, while on the contrary, the fertilizer amount in the middle row decreased.

When the angle was smaller than the $33^{\circ}$, the total mass of the middle export was almost greater than the both of sides. When the angle was $33^{\circ}$, the left export total mass was $11.36 \mathrm{~g}$; the middle one was $11.47 \mathrm{~g}$; the right was $11.55 \mathrm{~g}$ and the average was $11.46 \mathrm{~g}$. The value difference between the left and the average was $0.8 \%$; the middle and the average was $0.08 \%$; the right and the average was $0.7 \%$. The total mass of both sides kept increasing and be greater than the middle export from $34^{\circ} \sim 40^{\circ}$. At the same time, the both sides line kept same increasing trend and almost overlap, because the both sides was symmetry with each other. There was a similar variation between the middle of export and the sides export.

As a result, the most optimal parameter was $33^{\circ}$, which could be the fixed shunt part angle in the next experiment.

\section{(2) Shunt part simulation analysis}

The position of the shunt parts was divided into vertical and horizontal directions. In vertical direction, 
a single factor simulation experiment was designed. The $\mathrm{L}$ was used to denote the variable parameter in vertical direction. The test evaluation index was the total quantity of the three exports, respectively.

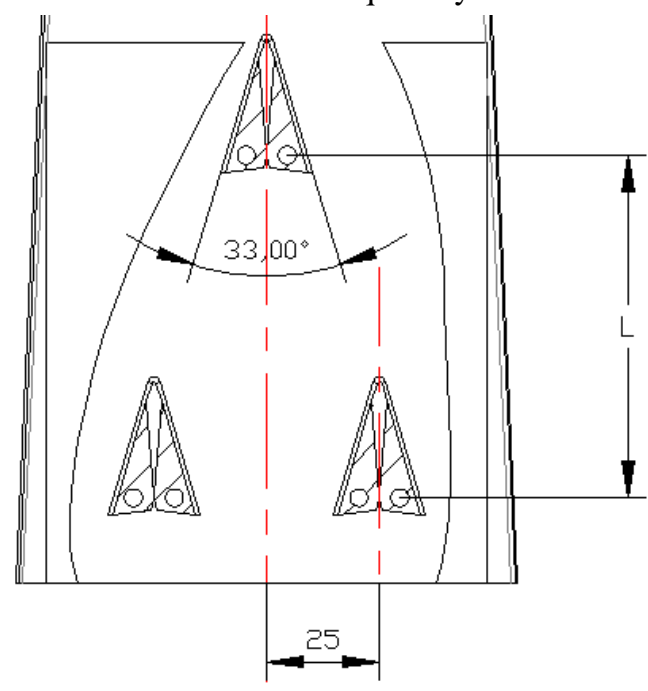

Fig.7 Vertical distribution variable parameter

The vertical distance, L's variable range was between $50 \mathrm{~mm}$ and $90 \mathrm{~mm}$, and the interval was $5 \mathrm{~mm}$. Simulation times was 2 seconds. The figure has shown as the increase of vertical distance, the both sides of the fertilize amount increased gradually, while the middle fertilize amount decreased gradually.

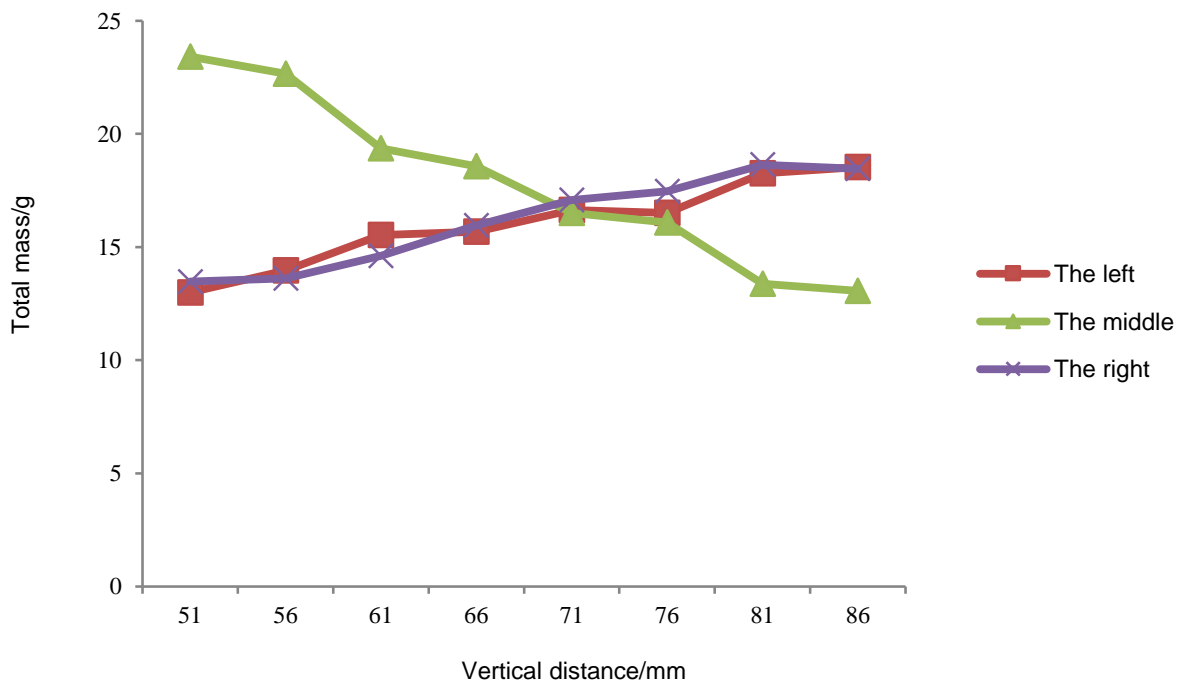

Fig.8 Simulation analysis of vertical position

When the distance was smaller than the $71 \mathrm{~mm}$, the total mass of the middle export was greater than the both sides. When the $\mathrm{L}$ was $71 \mathrm{~mm}$, the left export total mass was $16.64 \mathrm{~g}$; the middle one was $16.50 \mathrm{~g}$; the right was $17.09 \mathrm{~g}$ and the average was $16.8 \mathrm{~g}$. The value difference between the left and the average was $0.9 \%$; the middle and the average was $1.8 \%$; the right and the average was $1.7 \%$. The total mass of both sides kept increasing and be greater than the middle export from the $76 \mathrm{~mm}$. That was a similar situation when the $\mathrm{L}$ was between $71 \mathrm{~mm}$ and $76 \mathrm{~mm}$. At the same time, the both sides line kept the same increase trend and almost overlap, because the both sides was symmetry with each other. There 
was a similar variation between the middle of export and the sides export. So the vertical distance obtained an optimal range. But consider of the true error, the $\mathrm{L}$ should be equal to $76 \mathrm{~mm}$.

Then the horizontal position simulation was carried out. Two of shunt parts at the end shall be symmetrically distributed with the centerline of the device. The other one was on the centerline. The $\mathrm{H}$ was used to denote the variable parameter at the horizontal direction position.

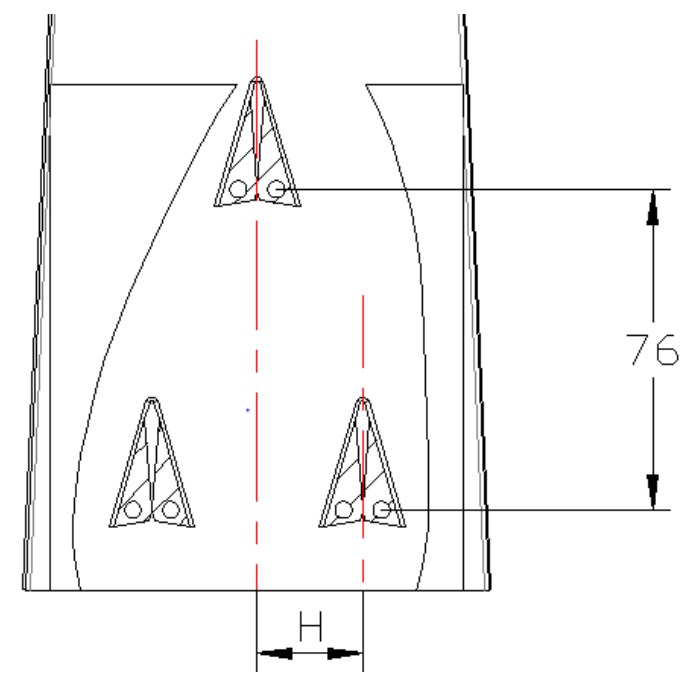

Fig.9 Horizontally distributed parameter variable

Among the eleven groups of parameters, the variable range was from 23 to 27 , with interval of $0.5 \mathrm{~mm}$. The other two parameters were $27 \mathrm{~mm}$ and $29 \mathrm{~mm}$. The corresponding simulated result was shown in figure 10.

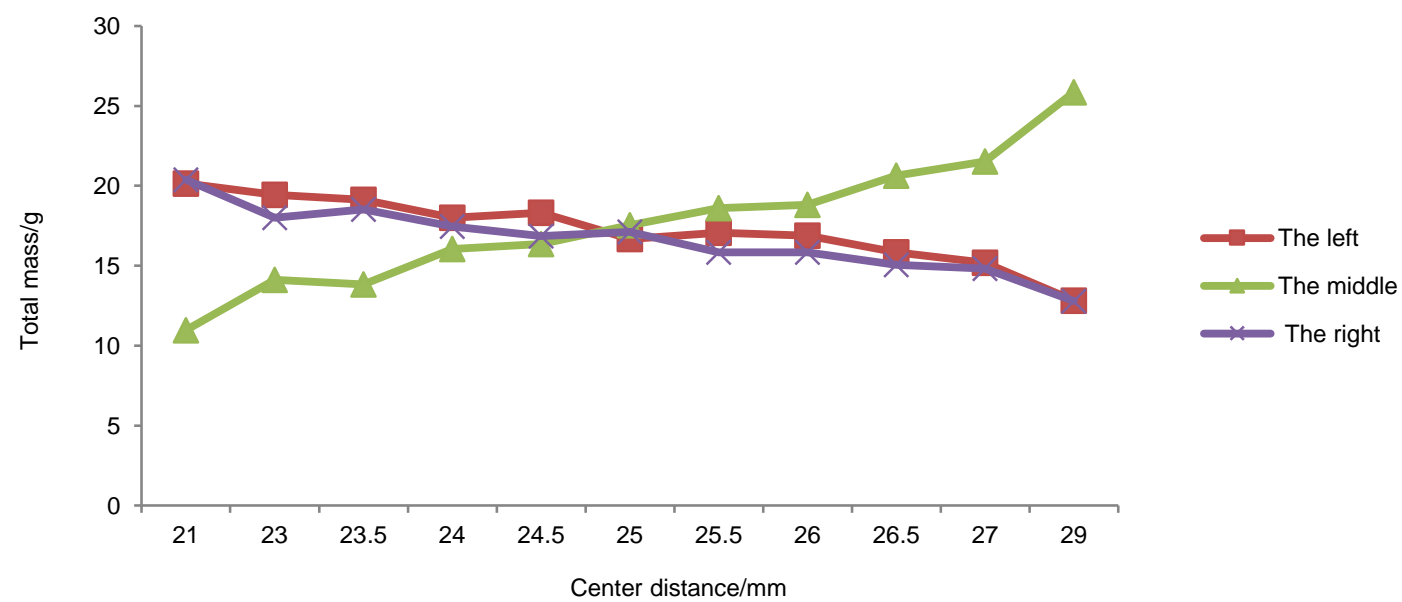

Fig.10 EDEM simulation analysis of horizontal position

With the increase of the center distance, the fertilizer amount on both sides exports gradually reduced, and the amount of fertilizer in the middle row of fertilizer increased gradually.

When the distance was smaller than the $25 \mathrm{~mm}$, the total mass of the middle export was smaller than the both sides. When the distance was the $25 \mathrm{~mm}$, the left export total mass was $16.67 \mathrm{~g}$; the middle one was $17.53 \mathrm{~g}$; the right was $17.12 \mathrm{~g}$ and the average was $17.11 \mathrm{~g}$. The value difference between the left and the average was $2.6 \%$, the middle and the average was $2.3 \%$, the right and the average was $0.05 \%$. The 
total mass of both sides kept increasing and being smaller than the middle export from $25 \mathrm{~mm}$ to $29 \mathrm{~mm}$. At the same time, the both sides line kept the same decreasing trend and almost overlapping, because the both sides was symmetry with each other. As a result, $25 \mathrm{~mm}$ was the most optimal parameter among the all of Horizontal position parameters.

\section{(3) Simulation of installation angle of fertilizer guide device}

The angle between the fertilizer guide groove and the horizontal surface was also a variable parameter. The fertilizer guide device was arranged between the $30^{\circ}$ angle to $50^{\circ}$. The simulation angle was from $32^{\circ}$ to $41^{\circ}$, with interval of $1^{\circ}$ and $50^{\circ}$.

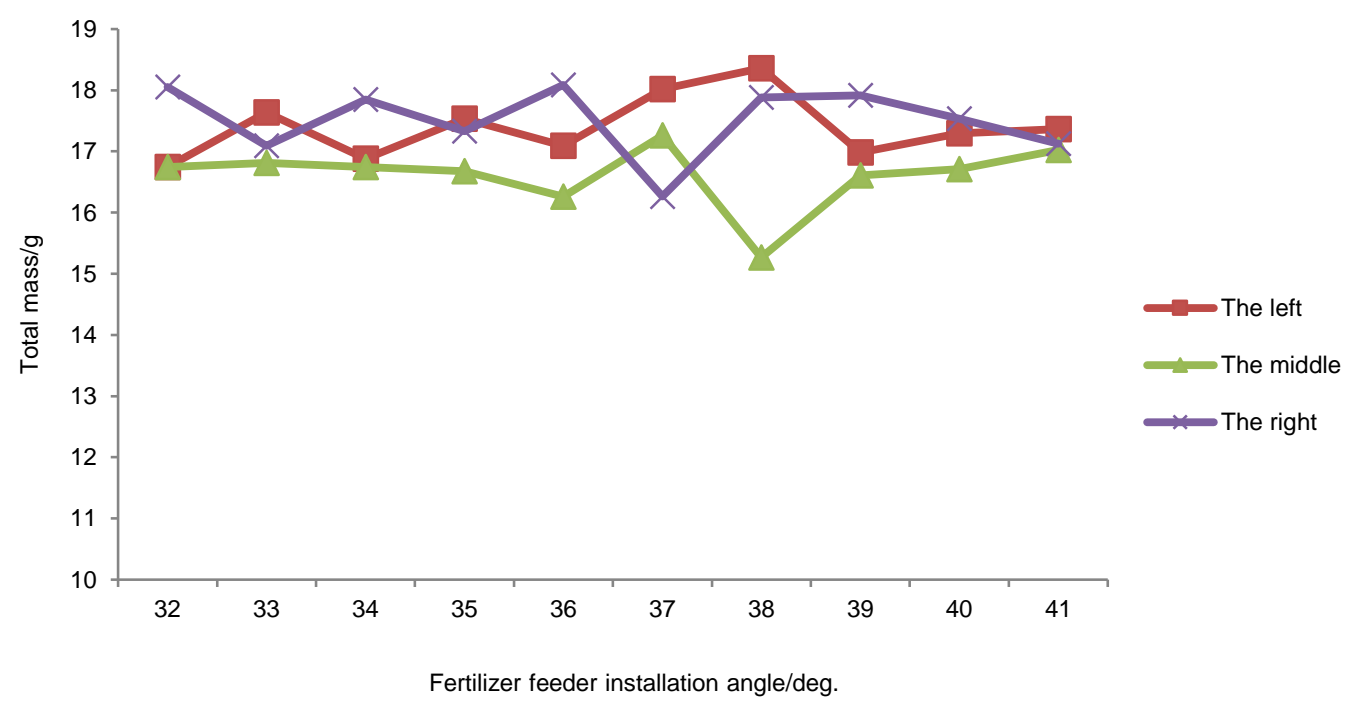

Fig.11 EDEM simulation analysis of fertilizer feeder installation angle

With the increase of the installation angle of the fertilizer guide groove, the fertilizer amount of the three outlets has no obvious increase or decrease, All of three exports total mass vary from $16 \mathrm{~g}$ to $18 \mathrm{~g}$, which remain constant from $32^{\circ} \sim 41^{\circ}$. And from the line chart, the three lines almost overlapped with each other and had no quite fluctuation. So there was no influence between the installation angle of the fertilizer guide device with the uniformity of fertilizer distribution. Meanwhile, the figure showed that quantity of the middle export was slightly lower than the both sides when all the parameters were the most optimal respectively. So in practical work, the shunt part opening angle or its position could be modified slightly to achieve the most optimal situation.

\section{Conclusion}

Through the above experiments and simulation, the following conclusions could be obtained.

(1) A new fertilizer guide device was designed. It could improve the fertilizer application evenly and accurately.

(2) When the shunt part opening angle was $33^{\circ}$, split between parts of vertical spacing was $76 \mathrm{~mm}$, the horizontal spacing was $25 \mathrm{~mm}$, the uniformity of the fertilizer distribution was best. The simulation results provided a reference for the design of the actual fertilizer guide device. 


\section{Acknowledgement}

This study was supported by the Key Research and Development Program of Shandong Province(2016CYJS03a01-1),Special Fund for Agro-scientific Research in the Public Interest (201303103), and the BAAFS youth foundation project (QNJJ201529).

\section{Reference}

1.Parish, R.L, Bracy, R.P, Morris Jr., H.F. Broadcast vs. band applications of fertilizer on vegetable crops[N].American Society of Agricultural Engineers(1997)

2.Yildirim, Y, Parish, R.L. Band application performance of single-disc rotary fertilizer spreaders[J].Applied Engineering in Agriculture. 29(2):149-153(2013)

3.ChenGuifen, Ma Li, Chen Hang. Research Status and Development Trend of Precision Fertilization Technology[J].Journal of Jilin Agricultural University.35(3):253-259(2013 )

4.ZengMin, Wang Changquan, Yang Jing. A Preliminary Overview of Site-specific Fertilization and Its Application Strategy in China[J].Journal of Sichuan Agricultural University.22(4):336-380(2004)

5.Li Jiannan. Current Situation and Thinking of Mechanized Fertilization Technology Development[J].Jiangsu Agricultural Mechanization.5(5):31-32(2014)

6.XuXin, Zhang Hao, Xi Lei, et al. Decision-making system for wheat precision fertilization based on WebGIS[J]. Transactions of the CSAE.27(Supp.2): 94-98(2011)

7.Wan Hanyang, Chen Haitao, Ji Wenyi. Anti-blocking mechanism of type 2BMFJ-3 no-till precision planter forwheat stubble fields[J].Transactions of the Chinese Society for Agricultural Machinery.44(4):64-70(2013)

8.PokrajacD, ObradoviCZ, Neural network-based software for fertilizer optimization in precision farming[J] .Neural Networks.3(1):2110-2115(2001)

9.Dun Guoqiang, Chen Haitao, Feng Yining, et al. Parameter optimization and test of key parts of fertilizer allocation device based on EDEM software[J]. Transactions of the Chinese Society of Agricultural Engineering, 32(7): 36-42(2016)

10.Wang Fulin, Shang Jiajie, Liu Hongxin, et al. Application of EDEM particles simulation technology on seed-metering device research[J]. Journal of Northeast Agricultural University. 44(2):110-114(2013)

11.Zhou Wenjun, Wei Hongbo. Simulation and Analysis of Belt Conveyor Based on EDEM Software[J].Coal Mine Machinery.34(5):89-90(2013) 